\title{
Derecho administrativo y transigibilidad
}

\author{
Juan Pablo Aguilar Andrade*
}

SUMARIO: 1. Sobre el concepto de transigibilidad en el Derecho Administrativo. 2. Transigibilidad y discrecionalidad. 2.1. La búsqueda de las materias transigibles 2.2. Transigibilidad y Derecho Administrativo. 3. Administración y arbitraje. 3.1. Actos administrativos y arbitraje. 4. El tema en la legislación ecuatoriana.

\section{Introducción}

En el primer número de esta revista, por una gentil invitación de Juan Manuel Marchán, publiqué un texto con algunas ideas sobre arbitraje y Derecho Administrativo; partí, en esa oportunidad, de una intuición que mantengo: el arbitraje no puede abordarse, cuando se trata del Derecho Público, con los mismos instrumentos que se utilizan en el mundo del Derecho Privado.

Lamentablemente, el texto no fue capaz de ser consecuente con las ideas de partida, pues el enfoque inicial que cuestionaba el uso de la noción de transigibilidad en el Derecho Administrativo cedió paso, en el desarrollo de la argumentación, al punto de vista tradicional sobre lo transigible y lo no transigible; como consecuencia, terminó sumándose a la idea de un mundo contractual en el que la transacción era posible, y un mundo de los actos administrativos en el que el ejercicio del poder público eliminaba cualquier posibilidad de transacción y, con ello, de arbitrabilidad.

En efecto, pese a que consideré que la noción de transigibilidad no era aplicable en el Derecho Administrativo o, al menos, debía ser matizada cuando de este último se trataba, no extraje las consecuencias de esa afirmación, sino que volví al viejo expediente de identificar, dentro de la actuación administrativa, lo que debía considerarse transigible y aquello que no lo era.

${ }^{*}$ Doctor en Jurisprudencia (Pontificia Universidad Católica del Ecuador), Magister en Derecho Administrativo (Universidad San Francisco de Quito), especialista en Derecho Público y contratación administrativa. Profesor titular de área de Derecho Público de la Universidad San Francisco de Quito. Árbitro de los centros de Arbitraje y Mediación de la Cámara de Comercio de Quito y de la Cámara de Comercio Ecuatoriano Americana. 
$\mathrm{Al}$ hacerlo, me sumé al punto de vista de quienes consideran que si bien el arbitraje es posible en el ámbito de lo contractual, en el que la base de la relación es el convenio entre las partes y no la orden unilateral de autoridad, no podía aplicarse en el caso de actos administrativos que, como manifestación del ejercicio del poder público, estaban fuera de aquello que la Administración podía considerar como transigible.

Este punto de vista, que entonces acepté sin profundizar sus consecuencias, encierra una grave dificultad: si los árbitros solo pueden pronunciarse en torno a controversias que no involucren actos administrativos, la sola presencia de estos últimos excluye su competencia; en otras palabras, es una de las partes contratantes la que puede, por su sola voluntad, dejar sin efecto el compromiso arbitral si, cuando se vislumbra una controversia, o se produce ésta, dicta un acto administrativo en relación con el tema.

Pensemos en un ejemplo concreto: el desacuerdo entre contratante y contratista sobre el cumplimiento de las especificaciones de un contrato. El contratista que, amparado en las estipulaciones contractuales sobre arbitraje, pretende iniciar el proceso correspondiente, vería frustradas sus expectativas si el contratante declara la terminación unilateral del contrato. ¿Qué sentido tiene una cláusula que ampara a las dos partes contratantes, pero cuya efectividad depende de la voluntad de una sola de ellas?

Es esto, precisamente, lo que me ha llevado a revisar mis propias conclusiones. Lo hago en las páginas que siguen, en las que busco extraer las últimas consecuencias de la intuición inicial que cuestiona el concepto de transigibilidad en el mundo del Derecho Administrativo. Como podrá verse, el resultado es bastante diferente a lo que sostuve en el artículo al que he hecho referencia y al punto de vista tradicionalmente aceptado por los administrativistas.

\section{Sobre el concepto de transigibilidad en el Derecho Administrativo}

La transigibilidad del objeto de una controversia es uno de los requisitos para que esta última pueda someterse a arbitraje; en el caso ecuatoriano, así consta tanto en el artículo 190 de la Constitución de la República, como en el primer artículo de la Ley de Arbitraje y Mediación. 
Esta exigencia, aplicada sin dificultad en el ámbito del Derecho Privado, se ha trasladado al Derecho Público como si de un principio general se tratara, sin tomar en cuenta si es, en efecto, un concepto que encaje en la lógica particular del Derecho Administrativo. De hecho, cuando este último acepta, sin beneficio de inventario, la noción de transigibilidad, nos coloca sobre una pista falsa, que pone el centro del problema en la identificación de lo que, para la Administración Pública, podría considerarse como materia arbitrable.

Para no entrar en la pista falsa es necesario cuestionarnos si la noción misma de transigibilidad puede tener cabida en el Derecho Administrativo o, al menos, en la materia que nos ocupa.

Esto exige partir del papel que cumple el concepto de transigibilidad en el arbitraje privado o, en otras palabras, entender la razón por la cual se limita el arbitraje a las controversias sobre derechos disponibles.

El artículo 2348 del Código Civil ecuatoriano, define a la transacción como un contrato "en que las partes terminan extrajudicialmente un litigio pendiente, o precaven un litigio eventual". No lo dice el Código, pero resulta evidente, que la transacción opera por medio de concesiones recíprocas que se hacen las partes involucradas en la controversia; como sostiene la jurisprudencia ecuatoriana, su esencia "reside en la renuncia que cada contratante hace de lo que cree su derecho a fin de evitar que un fallo judicial le quite todo a uno u otro" 1 .

Es evidente que esas concesiones solo pueden tener como objeto aquello que se encuentre en la esfera de lo disponible, aquello que sea transigible; solo pueden transigir, dice el artículo 2349 del Código Civil, "la persona capaz de disponer de los objetos comprendidos en la transacción”.

No parece, entonces, que transacción y arbitraje puedan identificarse. Mientras la primera implica ponerse de acuerdo en concesiones mutuas que permitan poner fin a una controversia, el segundo busca, no solucionar esta última, sino establecer las reglas para hacerlo.

1. Corte Suprema de Justicia (1992). Sentencia de tercera instancia. 30 de julio. Gaceta Judicial, serie XV, número 14, p. 4135. 
Esto es más claro si se toma en cuenta, como lo hace nuestra jurisprudencia, que terminar la controversia es la esencia de la transacción ${ }^{2}$, pues ésta no es otra cosa que la terminación de un litigio pendiente ${ }^{3}$. El sentido del arbitraje es distinto: se conviene en él, no para terminar una controversia, sino para trazar un camino que permita solucionarla.

En palabras de Leopoldo Aguilar Carvajal, la transacción se distingue "del compromiso en árbitros, porque en él se asientan las bases para que sea resuelto, mientras que en la transacción, mediante las concesiones recíprocas de las partes, se pone fin al asunto"4.

Conviene preguntarse, entonces, por qué la transigibilidad de una materia, aparece como un requisito necesario para que la misma pueda someterse a arbitraje.

A la hora de referirse a este tema, hay autores que lo consideran evidente: "no tiene sentido" el arbitraje sobre "derechos que por su naturaleza no son disponibles", dice MARTínEZ VÁsQUEZ", mientras que otros, como Faustino Cordón ${ }^{6}$, explican esa evidencia como algo relacionado con un principio básico del Derecho Procesal: el requisito de transigibilidad, dice, "es obvio atendiendo a la naturaleza dispositiva del arbitraje".

El principio dispositivo, según la doctrina, implica que es a las partes procesales a quienes corresponde "determinar el alcance y contenido de la disputa judicial"7 En el ordenamiento jurídico ecuatoriano, el artículo 19 del Código Orgánico de la Función Judicial lo recoge al disponer que los jueces "resolverán de conformidad con lo fijado por las partes como objeto del proceso".

Es a partir del principio dispositivo, que Patricio Aylwin deja en claro el fundamento del requisito de transigibilidad.

2. Ibidem.

3. Corte Suprema de Justicia (1933). Sentencia de tercera instancia. 18 de octubre. Gaceta Judicial, serie V, número 87, p. 2058.

4. J. LARrea Holguín, Derecho Civil del Ecuador, Quito: Corporación de Estudios y Publicaciones,tomo XIV, 2002, p. 355.

5. L. MARTÍNez VÁsQUeZ, La cláusula compromisoria en el arbitraje civil, Madrid: Civitas, 1991, p. 104.

6. F. CoRdón, El arbitraje en el derecho español: interno e internacional, Pamplona: Aranzadi, p. 68.

7. A. Troya, Elementos de Derecho Procesal Civil, Quito: Ediciones de la Universidad Católica, 1976, p. 136. 
En gran número de litigios está comprometido, más o menos directamente, el interés social; se hace necesario, en consecuencia, sujetarlos a solemnidades especiales que sean una garantía de que no se resolverá ni hará nada lesivo para las superiores conveniencia de la sociedad o los legítimos derechos de terceros. La investidura privada de los jueces árbitros los obliga a respetar solo los términos del compromiso, vale decir, la voluntad de los interesados, al margen de un eficaz control que vele por aquellos intereses; la facultad que tienen las partes de concederles poderes de arbitradores, les permite fallar con prescindencia de los mandatos imperativos de la ley. Esto bien puede ocurrir, sin daño alguno, en los asuntos en que entran en juego únicamente los intereses privados de los litigantes, pero no cuando pueden verse afectados el orden público, las buenas costumbres o los derechos de terceros ajenos al juicio. Por estas razones está negado a las partes el derecho de someter a compromiso los litigios que no sean de su interés puramente particular. Tal prohibición es consecuencia lógica de la naturaleza misma del juicio arbitral.

Entre privados, entonces, la autonomía de la voluntad se expresa en la posibilidad de configurar el alcance del arbitraje, esto es, de conferir poder a los árbitros para resolver sobre los asuntos que sean de interés de los litigantes. Es evidente, entonces, que ese poder tiene las mismas limitaciones propias de la autonomía de la voluntad, y no puede ejercerse sobre cuestiones que han sido excluidas del espacio en el que ella opera; en otras palabras, sobre aquello que para los particulares es indisponible.

Si esto es así, conviene preguntarse si los criterios anotados pueden aplicarse cuando se trata de la Administración Pública.

Para ello, partamos de los enfoques que tradicionalmente se han utilizado para abordar el tema de la transigibilidad en el Derecho Administrativos y que son básicamente dos, uno que gira alrededor de las potestades discrecionales, y otro que pretende definir una lista de materias transigibles o que pueden considerarse como tales. 


\section{Transigibilidad y discrecionalidad}

El primer enfoque parte de la distinción entre potestades regladas y potestades discrecionales, e identifica las primeras con lo no transigible y las segundas con lo transigible ${ }^{8}$.

Para el Derecho Administrativo, una competencia discrecional existe cuando la ley "deja al agente al cual se la confía, libre de apreciar, en vista de las circunstancias, si debe utilizarla y cómo"9. Siendo así, esa libertad de apreciar se identifica sin más con lo disponible, lo que puede parecer lógico, pero no es exacto.

Hay consenso en admitir que el ejercicio de la potestad reglada no puede ser objeto de arbitraje, lo que resulta completamente lógico si se toma en cuenta que en ese caso la administración no hace otra cosa que cumplir un expreso mandato legal, ante lo cual admitir la pretensión de transar sería tanto como dar a las normas el carácter de negociables. Lo mismo puede decirse de los elementos reglados de la potestad discrecional, esto es, aquellos que definen el marco dentro del cual se ejerce la discrecionalidad. Como sostiene Juan Manuel TraYter ${ }^{10}$ :

[...]no podrá nunca versar el arbitraje sobre actos administrativos reglados o sobre ejercicio de potestades discrecionales [...] en sus aspectos también reglados [...] Como hemos ya señalado, una de las notas esenciales del arbitraje es que las cuestiones litigiosas por él resueltas deben ser «materias de libre disposición», circunstancia que no concurre en los supuestos señalados.

Aunque legislaciones como la ecuatoriana mantienen que no cabe el control judicial de actos administrativos emitidos en ejercicio de potestades discrecionales (puede verse el artículo 6 de la Ley de la Jurisdicción Contencioso Administrativa), la doctrina más reciente apunta a superar este punto de vista y sostiene que no hay decisiones administrativas excluidas del control

8. J. M. TrAYTER, "El arbitraje de Derecho Administrativo", Revista de Administración Pública. Mayo-agosto. 1997, pp. 75-106.

9. J. RIVERo, Derecho Administrativo, Caracas: Universidad Central de Venezuela, 1984, p. 81.

10. J. M. Trayter, "El arbitraje de Derecho Administrativo", Revista de Administración Pública. Mayo-agosto. 1997, pp. 75-106. 
judicial; de hecho, el texto legal que se ha citado quedará derogado en mayo de 2016, al entrar en vigencia el nuevo código procesal. La polémica entre Tomás-Ramón Fernández, por un lado, y Luciano Parejo Alfonso y Miguel Sánchez Morón, por otro, ha definido con claridad la necesidad de terminar con la inmunidad del ejercicio de las potestades discrecionales; no está demás decir que esta polémica, como hace notar Manuel Atien$\mathrm{ZA}^{11}$ se basa en una diferencia "más de énfasis que propiamente teórica", pues los tres autores coinciden en la necesidad de controlar judicialmente la discrecionalidad.

El control de la discrecionalidad se exige porque el ejercicio de esta potestad no puede entenderse, a riesgo de convertirla en arbitrariedad, como libertad del titular del órgano administrativo para hacer lo que le parezca. En efecto, la ley, cuando asigna potestades discrecionales, no da manos libres a la administración sino que le permite optar por el camino que se considere más adecuado para satisfacer los intereses colectivos; es esto último lo que debe justificarse $y$, para ello, resulta esencial la motivación; lo no motivado, dice FERNÁNDEZ, se convierte en arbitrario ${ }^{12}$.

La decisión administrativa no es, entonces, una mera expresión de voluntad ni un simple querer del titular del órgano; solo se justifica si tiene como antecedente una evaluación detallada de razones y circunstancias, si se muestra como necesaria para el cumplimiento de los fines de orden público a los que se dirige.

Hay en lo discrecional un espacio para evaluar la procedencia de dos o más soluciones igualmente válidas, hay un "cierto margen de apreciación" que permite analizar opciones, pero en todo caso la decisión debe justificarse como necesaria para el interés colectivo y este último no es transable; en consecuencia, la decisión se justifica en función de fines de orden público y negociarla sería tanto como negociar esos fines.

En otras palabras, que la decisión del titular del órgano administrativo no venga establecida de antemano por la norma, sino que deba adoptarse a partir del abanico de opciones que esa norma plantea, no pone

11. M. AtienZA, Cuestiones judiciales, México: Fontamara, 2004, p. 53.

12. T. FERnÁNDEZ, De la arbitrariedad de la administración, Madrid: Civitas, 2002, p. 87. 
a los órganos administrativos en el espacio de la autonomía de la voluntad. En efecto, el hecho de que se les confiera un espacio más amplio para la toma de decisiones, no implica que sean libres de actuar como mejor les parezca; su actuación, siempre y en todo caso, debe someterse al cumplimiento de los objetivos de orden público para los cuales se les confiere la potestad.

En otras palabras, cuando se piensa que discrecionalidad equivale a transigibilidad, se olvida que en la primera no hay un ejercicio de libertad del agente, sino un espacio más amplio de decisión, limitado siempre por expresos mandatos normativos; como bien explica nuestra jurisprudencia, el margen de libertad del que goza la administración en el ejercicio de sus potestades discrecionales no es extra legal (Corte Suprema de Justicia, 2007).

Resulta claro, entonces, que la supuesta identificación entre lo transigible y lo discrecional, carece de fundamento.

\subsection{La búsqueda de las materias transigibles}

Hay un segundo enfoque en materia de transigibilidad de las actuaciones administrativas, aquél que distingue los actos administrativos propiamente tales, de otra clase de actividades que puede realizar la Administración para gestionar la cosa pública.

CHILlón y Merino, por ejemplo, se preguntan “¿por qué no pueden ser arbitrables el resto de los actos de gestión en los que la administración se relaciona con los particulares?"13.

Para responder la pregunta enumeran una serie de actividades en las que no estaría en juego el ejercicio del poder público, sino la gestión de asuntos patrimoniales; en ellas, la Administración actuaría como si fuera privado. Los autores citados incluyen en la lista la que denominan "actividad privada del Estado", los temas de responsabilidad patrimonial, los contratos, los bienes y derechos patrimoniales y los bienes y derechos económicos no patrimoniales.

13. J. M. CHILlón y J. F. MERINO, Tratado de arbitraje privado interno e internacional, Madrid: Civitas, 1991, pp. 176-180. 
Para responder la pregunta enumeran una serie de actividades en las que no estaría en juego el ejercicio del poder público, sino la gestión de asuntos patrimoniales; en ellas, la Administración actuaría como si fuera privado. Los autores citados incluyen en la lista la que denominan "actividad privada del Estado", los temas de responsabilidad patrimonial, los contratos, los bienes y derechos patrimoniales y los bienes y derechos económicos no patrimoniales.

Marta García PéRez analiza este tema desde las diversas formas que adopta la identificación de las materias transigibles: la determinación de un criterio general o la elaboración de una lista de materias, ya a priori, desde la legislación, ya a posteriori, desde la jurisprudencia ${ }^{14}$.

En todos los casos, lo que está en juego en este enfoque es la distinción entre la actividad administrativa desde el ejercicio del poder de imperio y la actividad que, repitiendo a CHILlón y Merino, podríamos calificar como "privada del Estado". Básicamente, la Administración no solo actúa en ejercicio de las potestades exorbitantes que le confiere el Derecho Administrativo, sino que también aplica, para determinadas actividades y relaciones, la reglas del ordenamiento privado; piénsese, por ejemplo, en las normas que rigen para los bienes de "dominio privado" de la administración o el caso de la contratación, en el que los entes administrativos dejan de lado su poder de dar órdenes unilaterales y se sirven de un instrumento propio del Derecho Privado.

El problema es que la distinción no puede ser tan tajante como aparece a primera vista, pues la presencia de la Administración introduce importantes cambios en los instrumentos de derecho privado que utiliza.

La celebración de un contrato de compraventa es el medio que utilizan las empresas o administraciones privadas para adquirir la propiedad del solar sobre el que construir la sede social donde desarrollan la dirección de sus actividades mercantiles (de las naves industriales donde fabrican bienes o de los establecimientos en los que prestan servicios). Las Administraciones Públicas también pueden servirse

14. M. GARCÍA PÉREZ, Arbitraje y Derecho Administrativo, Pamplona: Aranzadi, 2011, pp. 48-56. 
de ese medio jurídico bilateral y negociado en condiciones de igualdad, pero además del contrato de compraventa pueden utilizar la potestad expropiatoria para adquirir ese mismo solar de forma coactiva y forzosa ${ }^{15}$.

Como puede verse, por más que se pretende distinguir en la Administración un actuar propiamente público de otro privado, o asimilable al privado (lo que me hace recordar la desechada idea de la doble personalidad del Estado), la presencia de las potestades administrativas nos devuelve de lleno al problema que se pretende solucionar.

En efecto, podemos convenir en que los temas contractuales caen dentro del espacio de lo transigible, y esa es precisamente la consideración que ha llevado a admitir que se trata de temas arbitrables, pero la presencia de los poderes exorbitantes de la Administración mantiene inalterado el problema principal: ¿qué pasa cuando la ejecución contractual exige el ejercicio de esos poderes exorbitantes?

\subsection{Transigibilidad y Derecho Administrativo}

Los enfoques que se ha analizado dejan de lado un aspecto fundamental: la noción de transigibilidad se explica en el ámbito del Derecho Privado, pero no encaja en los moldes del Derecho Público; de ahí las dificultades con que tropieza la pretensión de darle vida en un ambiente en el que se respira un aire que para ella resulta venenoso.

Me explico.

La transigibilidad es una institución que tiene pleno significado en el mundo del Derecho Privado, porque ese es el mundo de la libertad individual y de la autonomía de la voluntad. La creación de espacios de lo irrenunciable es necesaria, precisamente, porque sin esos límites la voluntad privada puede invadir mundos que el ordenamiento jurídico prefiere mantener intocados.

15. D. BlanQuer, Curso de Derecho Administrativo, Valencia: Tirant lo Blanc, 2005, p. 52. 
La regla general, dice Pérez Guerrero, es la libertad individual, y sería violar esa libertad "el poner diques a sus decisiones sean las que fueren, si ellas no atacan a la esfera de la libertad de otro. Esa esfera de la libertad ajena está relacionada con la noción de orden público, que incluye aquello que el sistema jurídico "considera esencial en la organización de la sociedad"; el orden público y esa organización social "se desquician si se permite renunciar a los correspondientes derechos" 16 .

Estas consideraciones sobre libertad humana y autonomía de la voluntad, y sobre los límites que se imponen a ellas para salvaguardar el Orden Público, no tienen cabida cuando se trata de la Administración Pública.

En efecto, esta última no actúa sobre la base del principio de libertad sino que está sometida al principio de legalidad; esto es, no es libre de hacer lo que le parezca más conveniente, sino que está limitada a hacer aquello que expresamente le encargue el ordenamiento jurídico.

Así, pues, no hay [...] ningún espacio "franco o libre de Ley", en que la Administración pueda actuar con un poder ajurídico y libre. Los actos y las disposiciones de la Administración, todos, han de "someterse a Derecho", han de ser "conformes" a Derecho. El desajuste, la disconformidad, constituyen "infracción del Ordenamiento jurídico" y les priva actual o potencialmente (distinción entre nulidad y anulabilidad), de validez. El Derecho no es, pues, para la Administración una linde externa que señ ale hacia fuera una zona de prohibición y dentro de la cual pueda ella producirse con su sola libertad y arbitrio. Por el contrario, el Derecho condiciona y determina, de manera positiva, la acción administrativa, la cual no es válida si no responde a una previsión normativa ${ }^{17}$.

La Administración, dice el artículo 226 de la Constitución de la República, ejerce "solamente las competencias y facultades [...] atribuidas en la Constitución y la ley". En consecuencia, no tiene derechos, sino potestades, no obra libremente sino que requiere una habilitación legislativa previa,

16. A. PÉrez Guerrero, Fundamentos del Derecho Civil Ecuatoriano, Quito: Universidad Central del Ecuador Editorial Universitaria, 1953, pp. 224-225.

17. E. García De Enterría y T. Fernández, Curso de Derecho Administrativo, Madrid: Civitas, 2001, p. 440. 
esto es, actúa solo en la medida en que una norma le autoriza a hacerlo. La actividad administrativa no es ejercicio de libertad, sino "de un poder atribuido previamente por la Ley y por ella delimitado y construido" 18 en esa medida, no es un poder libre sino un poder sometido a la norma y, como tal, "obligado a dar cuenta de su efectivo servicio a la función para la que fue creado" 19 .

Mientras los particulares, en ejercicio de la autonomía que les es propia, pueden disponer libremente de sus derechos en tanto no exista prohibición expresa para ello, los órganos administrativos no se mueven en el ámbito de sus intereses individuales, sino en el del interés de la comunidad.

Los rasgos que configuran los derechos subjetivos se distinguen de las notas características de las potestades de que están investidas las Administraciones Públicas [...] El contenido de los derechos subjetivos se descompone en "facultades" [...] que como su propio nombre indica son de ejercicio voluntario o facultativo [...].

A diferencia de los derechos subjetivos que son renunciables y transmisibles porque satisfacen intereses de su titular, las potestades son intransmisibles e irrenunciables porque están orientadas a satisfacer el interés ajeno [en el caso que aquí importa las potestades administrativas no satisfacen intereses particulares de la propia Administración Pública, sino que tienen por finalidad satisfacer los intereses de los ciudadanos o intereses generales]. Las potestades con un título fiduciario en beneficio de un tercero, y por ello son de obligado ejercicio ${ }^{20}$.

Estas diferencias básicas entre el espacio público y el privado, se dejan de lado cuando se pretende aplicar en ambos un concepto, el de transigibilidad, que es completamente extraño al primero.

En efecto, si la noción de transigilidad se hace necesaria para establecer límites al ejercicio de la libertad individual, ¿qué sentido tiene en un ámbito en el que los actores no gozan de libertad, sino que actúan a partir de las competencias que les han sido previamente asignadas?

18. Ibídem

19. T. FERNÁNDEZ, De la arbitrariedad de la administración, Madrid: Civitas, 2002, p. 89.

20. D. Blanquer, Curso de Derecho Administrativo, Valencia: Tirant lo Blanc, 2002, p. 205. 
Ninguno. Cuando se trata de la Administración no nos encontramos ante derechos libremente disponibles, ante un problema de transigibilidad, sino ante la existencia o no existencia de competencias legalmente atribuidas.

En otras palabras, la noción de transigibilidad, en el sentido de límite a la libertad individual, como se la entiende en el Derecho Privado, no se aplica en el Derecho Administrativo, porque no cabe utilizar una institución que busca poner límites al ejercicio de derechos que, en el caso de los órganos administrativos, no existen.

\section{Administración y arbitraje}

La exigencia de que el arbitraje solo pueda pactarse sobre materia transigible se explica, conforme se ha visto, por la necesidad de impedir que la autonomía de la voluntad invada los espacios de lo irrenunciable. Precisamente porque los privados son libres de actuar de acuerdo con sus intereses, se requiere establecer un límite que proteja lo que se considera parte del interés colectivo y, como tal, pertenece al mundo de lo indisponible.

Pero si de lo que se trata es de proteger determinados espacios del ejercicio de la autonomía de la voluntad, el instrumento para hacerlo pierde su razón de ser cuando esa autonomía desaparece. Y eso, precisamente, es lo que pasa si uno de los actores es la Administración Pública, que no es titular de derechos sino que ejerce competencias, actúa por mandato legal y no por su libre querer $y$, en esa medida, no requiere un control para el ejercicio de una autonomía de la voluntad de la que carece.

En el ámbito del Derecho Público, será la legislación la que evalúe qué competencias se deben asignar a los entes administrativos y, obviamente, esas competencias se entregan sin más limitaciones que las que la propia norma establece.

Mientras en el Derecho Privado la libertad puede ejercerse sin restricciones y es la ley la que debe establecer estas últimas conforme a los intereses sociales, en el Derecho Público no hay libertades presupuestas sino competencias asignadas, siendo la ley la que las crea, fija sus límites y sus alcances. 
Sin libertad de por medio, no hay que preguntarse qué es aquello sobre lo cual esa libertad no puede ejercerse y, por lo tanto, la idea de transigibilidad carece de sentido en el arbitraje administrativo.

La pregunta, en este último, no pasa por el espacio de lo indisponible, sino por el alcance de las potestades que la ley asigna y que constan en la propia norma.

Parece lógico sostener, según ésto, que la posibilidad de que los asuntos en los que interviene la Administración puedan someterse a arbitraje, depende de que exista una norma que confiera la potestad de celebrar el correspondiente convenio arbitral. Cuando esa norma existe, el tema es arbitrable, sin más limitaciones que las que la misma norma establece.

En otras palabras, conferida una potestad no hay que buscar en ella límite alguno; es la ley que regula la potestad, la que debe expresamente excluir determinados asuntos de su ejercicio y, si no lo hace, no pueden considerarse excluidos.

La potestad de someter una controversia a arbitraje, entonces, incluye todo lo relacionado con ella, salvo excepción expresa. Mientras en el Derecho Privado se recurre al arbitraje en ejercicio de la autonomía de la voluntad, siendo la ley la que pone límites a este ejercicio de libertad, en el Derecho Público la competencia para recurrir al arbitraje se entrega como un todo, al que no hay que buscar más límites que los que consten en la propia norma.

Si volvemos al problema de los contratos administrativos, la autorización para que las controversias contractuales se sometan a arbitraje incluye toda controversia, con independencia de que la misma se relacione con actos administrativos de ejecución contractual.

Esto nos lleva a un tema fundamental: la arbitrabilidad de las controversias derivadas de actos administrativos, aunque no exista un contrato de por medio. 


\subsection{Actos administrativos y arbitraje}

Como se ha visto, la noción de transigibilidad, que ocupa un espacio importante en el arbitraje privado, pierde sentido cuando se trata de la Administración Pública. Mientras que en el primero la materia arbitrable la define la autonomía de la voluntad de los interesados, limitada por los mandatos legales, en el segundo esa materia depende de un mandato legislativo.

Si lo vemos desde el principio dispositivo, en el arbitraje privado son las partes las que señalan a los árbitros los asuntos sobre los cuales debe versar su decisión; cuando interviene la Administración Pública, claro que existe un contrato que señala la materia arbitrable, pero esa materia ha sido definida previamente por un mandato legal. En otras palabras, el principio dispositivo se aplica, no como el resultado del ejercicio de la libertad individual, sino como el cumplimiento de un mandato legal.

Lo transigible existe en el Derecho Administrativo, pero no como un atributo inmanente a la personalidad de los entes públicos, sino como una competencia expresamente asignada por las normas; no hay temas "naturalmente" transigibles o no transigibles; es la ley la que establece qué materias y en qué condiciones pueden ser objeto de transacción. Lo mismo ocurre en el caso del arbitraje: procede cuando una ley establece su posibilidad.

Pero transigibilidad y arbitraje son independientes entre sí y, a diferencia de lo que ocurre en el Derecho Privado, el primero no es requisito previo del segundo, ni sirve para establecerle límites. Una y otro existen porque la ley lo permite y es ella la que define lo que puede hacerse en cada caso.

Como consecuencia, en el Derecho Público la arbitrabilidad no tiene que ver con la transigibilidad y, para establecer si una materia es arbitrable, lo que se debe establecer es si existe una ley que la defina como tal, y no si los asuntos a los que se refiere pueden calificarse o no como renunciables.

De hecho, la búsqueda de materias renunciables en el Derecho Administrativo carece de sentido pues, como se dijo ya, los entes públicos no son titulares de derechos que puedan renunciar, sino que ejercen competencias obligatorias. 
El problema no pasa, entonces, por definir un espacio de lo renunciable, sino por establecer los temas que se considera arbitrables; y esto no tendrá que ver con el hecho de que esté o no de por medio el ejercicio del poder público, sino con las conveniencias que puedan existir en un momento determinado.

Cuando el arbitraje involucra a un ente público, los árbitros no están ligados por un mandato nacido de la voluntad autónoma de quienes pactaron el arbitraje, sino que se rigen por los expresos mandatos legales sobre la materia que se somete a su conocimiento. Esto quiere decir que, en estos casos, un árbitro no evalúa temas renunciables sino que, como lo haría un juez contencioso administrativo, analiza la situación desde el punto de vista de la legalidad.

No voy a profundizar en el tema, pero parece claro, en este punto, que así como un juicio contencioso administrativo, que se pronuncia sobre la legalidad de un acto administrativo, no tiene nada que ver con el concepto de transigibilidad, lo mismo ocurre con un arbitraje sobre el mismo tema. De hecho, tanto el juez contencioso administrativo, como el árbitro, no pueden, a la hora de analizar un acto administrativo, partir de consideraciones diferentes a la legalidad del mismo. En otras palabras, aunque esto habrá que matizarlo en el caso del arbitraje internacional, la mirada sobre el acto administrativo será la misma, tanto desde los ojos del juez, como desde los del árbitro.

La consecuencia parece clara: no hay actuación administrativa que no pueda, en principio, ser sometida a arbitraje; es la ley la que debe definir la conveniencia de hacerlo o no en casos determinados.

\section{El tema en la legislación ecuatoriana}

Si no hay materias "naturalmente" transigibles y, por ello, "naturalmente" arbitrables, hay que consultar la legislación de cada país, para establecer los límites de la potestad jurisdiccional de los árbitros en temas de Derecho Administrativo. Reviso, a continuación, el caso concreto del Ecuador, donde el arbitraje tiene rango constitucional desde 1996. 
Para entender las normas constitucionales sobre arbitraje, y aplicarlas a los temas propios del Derecho Administrativo, es imprescindible relacionarlas con otros mandatos de la Norma Suprema, en los que se hace referencia a las potestades jurisdiccionales en materia de legalidad de actos administrativos.

La reforma constitucional aprobada en agosto de 1983, codificada en 1984 y vigente a partir del 10 de agosto de ese año, estableció, en los siguientes términos, en el número 3 de su artículo 96, el principio de unidad jurisdiccional:

Se establece la unidad jurisdiccional. Por consiguiente, todo acto administrativo generado por la administración central, provincial, municipal o de cualquier entidad autónoma reconocida por la Constitución y las leyes, podrá ser impugnado ante los Tribunales Fiscal y de lo Contencioso Administrativo, en la forma que determine la ley.

En la codificación constitucional de 1993, este artículo pasó a ser el número 97 y se mantuvo como artículo 122 en la codificación de 1996. En esta última, sin embargo, se agregó un artículo, el 118, que tuvo su origen en la reforma constitucional de diciembre de 1995, y cuyo texto era el siguiente:

Con arreglo al principio de unidad jurisdiccional, el ejercicio de la potestad judicial corresponde exclusivamente a los magistrados, jueces y tribunales determinados en la Constitución, las Leyes y en los tratados internacionales. [...] Se reconoce el sistema arbitral, la negociación y otros procedimientos alternativos para la solución de las controversias.

La codificación constitucional que entró en vigencia a partir del 10 de agosto de 1998 mantuvo disposiciones similares: estableció en el artículo 191 la unidad jurisdiccional y, en los mismos términos, el reconocimiento de los medios alternativos de solución de conflictos; además, en un artículo independiente, el 196, dispuso:

Los actos administrativos generados por cualquier autoridad de las otras funciones e instituciones del Estado, podrán ser impugnados ante los correspondientes órganos de la Función Judicial, en la forma que determina la ley. 
En la Constitución vigente se regula también el tema en el artículo 176:

Los actos administrativos de cualquier autoridad del Estado podrán ser impugnados, tanto en la vía administrativa como ante los correspondientes órganos de la Función Judicial.

¿Implican las normas transcritas que sólo los tribunales estatales son competentes para conocer sobre la legalidad de los actos administrativos? Parece que sí.

Si atendemos a las normas que rigieron entre 1996 y 1998, el mandato es claro: la potestad judicial corresponde a magistrados, jueces y tribunales estatales e internacionales, si bien se reconoce el sistema arbitral. En lo que tiene que ver con los actos administrativos, la regla era absolutamente clara: "todo acto administrativo [...] podrá ser impugnado ante los Tribunales Fiscal y de lo Contencioso Administrativo".

El uso de la palabra "todo" no dejaba lugar a duda: los tribunales Fiscal y de lo Contencioso Administrativo, según la naturaleza del acto de que se trate, eran los únicos competentes para conocer impugnaciones contra actos administrativos.

Sin embargo, es posible que genere confusión el uso de la palabra "podrá". Esto porque puede argumentarse que si la norma establece que los actos administrativos "podrán ser impugnados" ante estos jueces, nos encontramos ante un típico caso de discrecionalidad, que haría de la jurisdicción contencioso administrativa una posibilidad, dependiente de la elección del demandante.

El sentido de la norma, sin embargo, no es ese. En realidad, la redacción potestativa tiene que ver, no con la existencia de vías distintas de la contencioso administrativa, sino con el hecho de que iniciar una acción ante los órganos jurisdiccionales es un derecho y no una obligación. En otras palabras, el destinatario de un acto administrativo tiene la posibilidad de impugnarlo (o no hacerlo), y el "podrá" del texto legal no se refiere a la vía de impugnación sino a la facultad que tiene quien se considere afectado por un acto administrativo, para impugnarlo. 
La norma, por otra parte, abarca también los actos administrativos expedidos por la administración contratante, en el curso de la ejecución de un contrato administrativo. Esto porque, cuando se habla de "todo acto administrativo", no se hace distinción alguna entre las diversas clases de actos $y$, en consecuencia, debemos entender que se refiere a todos ellos.

Cuando la Ley de Arbitraje y Mediación se promulgó en 1997, su artículo 4 autorizó a las entidades del sector público a someter al arbitraje controversias de carácter contractual, pero esta autorización, obviamente, no podía ir más allá del marco constitucional, esto es, no podía incluir actos administrativos, ni aún los expedidos como parte de la ejecución contractual, porque esos actos eran parte de "todos" los actos administrativos que conforme la Constitución solo podían impugnarse ante los jueces estatales.

No me cabe duda, conforme lo dicho, que entre 1996 y 1998, por mandato constitucional, ningún árbitro podía resolver sobre la legalidad de actos administrativos, ni aún en el caso de que estos últimos se hubieren expedido dentro de una relación contractual.

El texto constitucional de 1998, como se ha visto, es diferente de los que rigieron antes de él pero, me parece, no implica ninguna modificación en el tema que nos ocupa. En efecto, el cambio fundamental radica en que no se habla de "todo acto administrativo", sino únicamente de "actos administrativos". Esta, sin embargo, es solo una diferencia de énfasis, pues de todos modos no se establecen distinciones constitucionales en el ámbito de los actos administrativos ${ }^{21}$ y eso nos lleva a entender, aunque no se use la palabra, que se hace referencia a todos.

Si esto ocurre con el texto constitucional de 1998, parecería que lo mismo habría que sostener en el caso de la Constitución vigente, cuya norma sobre la materia es similar a la que la precedió. De ser así, los textos constitucionales que se han analizado servirían de fundamento para sostener que ningún acto administrativo, incluso los expedidos en el curso de la ejecución contractual, puede ser objeto de la decisión de árbitros.

21. En realidad hay una diferencia, pues el mandato constitucional excluye los actos administrativos de los órganos de la Función Judicial. Para el tema que nos ocupa, sin embargo, esta diferencia no viene al caso. 
Hay, sin embargo, elementos adicionales en la Constitución de 2008 que llevan a una interpretación diferente.

En el caso de los textos constitucionales anteriores había dos claros mandatos: i) los actos administrativos solo pueden impugnarse ante los jueces de lo contencioso administrativo; y, ii) la ley puede establecer los casos en que se admite recurrir al sistema arbitral para la solución de controversias sobre materias transigibles. Esto quiere decir que la ley reguladora del arbitraje tenía dos límites que no estaba autorizada a franquear: el primero tenía que ver con el carácter transigible de la materia y el segundo con el hecho de que los árbitros no podían pronunciarse sobre la legalidad de actos administrativos, tengan o no el carácter de actos de ejecución contractual.

La Constitución vigente, si bien establece los mismos límites que sus predecesoras, incluye reglas adicionales que los amplían.

En efecto, conforme se ha visto, la Norma Fundamental establece que el arbitraje procede "en materias en las que por su naturaleza se pueda transigir" (Art. 190:1), y que los jueces competentes para conocer sobre la legalidad de los actos administrativos son los jueces contencioso administrativos (Art. 173), pero, a diferencia de textos constitucionales anteriores, reconoce expresamente la posibilidad de que las controversias derivadas de contratos públicos, se sometan a arbitraje: "en la contratación pública procederá el arbitraje en derecho, previo pronunciamiento favorable de la Procuraduría General del Estado, conforme a las condiciones establecidas en la ley", dice el artículo 190.

La situación, entonces, difiere de la que existía antes de la vigencia del nuevo texto constitucional. Mientras con la Constitución anterior la ley podía admitir que la administración utilice el sistema arbitral, siempre que ello no implique juzgar sobre la legalidad de actos administrativos, la vigente establece una regla general, que excluye los temas no transigibles y los actos administrativos, y un caso especial: el arbitraje en derecho en temas de contratación pública. 
Bien puede sostenerse, ante ésto, que la referencia expresa a los contratos públicos se explica porque, con ella, se establece un ámbito específico, al que no se aplica la regla general sobre el control de legalidad de los actos administrativos. En otras palabras, la jurisdicción contencioso administrativa es la llamada a conocer controversias sobre actos administrativos, pero en el caso de los contratos, los árbitros pueden resolver todas las controversias que de ellos surjan, sin que se excluyan de esta facultad los actos administrativos de ejecución contractual.

Esto, además, porque si la Constitución hubiera querido establecer diferencias entre los temas contractuales arbitrables o no arbitrables, lo habría expresado en el texto; al no hacerlo, debemos entender que la norma ampara a todas las controversias contractuales, sin excepción. 